\title{
HIGH-RESOLUTION TRAVEL-TIME TOMOGRAPHY USED TO DELINEATE A SHALLOW WASTE DISPOSAL SITE
}

\author{
Eva Lanz, Hansruedi Maurer, Jörg Ansorge, Alan Green \\ Institute of Geophysics, ETH-Hönggerberg, 8093 Zürich, Switzerland \\ eva@augias.ig.erdw.ethz.ch
}

\begin{abstract}
INTRODUCTION
In Switzerland, large quantities of waste are buried in glacial and glaciofluvial sediments. These same sediments comprise two-thirds of the country's aquifers and thus contain important sources of drinking water. To assess the potential for environmental contamination, the boundaries of the buried waste sites (i.e. their lateral extents and depths) must be well known. The depths of the sites are of particular interest for judging if the groundwater table is within or below the waste.
\end{abstract}

The possibilities and limitations of a wide variety of geophysical techniques for characterizing buried waste disposal sites have been explored at the Stetten landfill in northern Switzerland (Lanz et al., 1994, 1996). Lateral boundaries of the landfill have been determined using magnetic and electromagnetic methods, and for the precise delineation of its depth we have developed and implemented a high-resolution travel-time tomography technique. Particularly interesting areas have been investigated in detail with 3-D georadar. Here, we present results of the travel-time tomography experiment.

\section{SEISMIC TRAVEL-TIME TOMOGRAPHY}

Seismic data collected directly over a landfill are often characterized by strong scattering and/or anelastic effects that preclude the reflection imaging of its base. By comparison, refracted wavefields have the potential to provide reliable information on this parameter. To obtain meaningful results from refraction surveys, several problems peculiar to landfills have to be solved: (i) waste sites are often located within or near to populated areas, such that high background noise is common, (ii) travel-time anomalies are expected to be of the order of a few milliseconds or less, thus requiring high precision picking of the first arrivals, and (iii) structures to be investigated are likely to be highly heterogeneous, requiring the application of appropriate tomography algorithms. In order to address these problems, several field and synthetic tests were carried out before conducting the actual field work.

Accurate travel-time calculations of waves traveling through 2- and 3-D media are important elements of tomographic inversions. During the past few years several fast finite-difference eikonal solvers have been developed. They are able to propagate wavefronts through highly heterogeneous media and are therefore well-suited for our purposes. We have adopted a modified version of the brute force mapping scheme proposed by Schneider et al. (1992). Beside robust calculations of travel-times, the modified mapping scheme also provides accurate reconstruction of the ray paths. 
In refraction surveying, the ray density and number of crossing rays generally decrease with increasing depth. To account for resulting decreases of spatial resolution, the model cell size should increase with depth. In contrast, algorithms for computing travel times and ray paths usually require a regular and evenly spaced grid. To satisfy these competing requirements, we use a model comprising a uniform grid of relatively small cells for the travel-time calculations, and then join deeper cells to form larger model cells for the inversion.

Due to the strong interdependence of ray coverage and velocity structure, the tomographic inversion problem is strongly non-linear. For successful delineation of subsurface structures, appropriate choices of the initial inversion models may be critical. We have adopted the socalled optimum 1-D reference model approach (Kissling et al., 1994), in which it is assumed that most earth structures can be represented to a first approximation by 1-D models (i.e. velocity and slowness only vary with depth). The initial $1-D$ velocity models are then used as a basis for computing the 2- and 3-D velocity tomograms.

\section{THE STETTEN TEST SITE}

The Stetten landfill is situated in a valley eroded by glaciers. High-resolution seismic reflection data have provided information on the gross structure of the host sediments (Lanz et al., 1996), which comprise complex units of till and outwash overlying lacustrine sediments. The outwash includes channels and lenses of clean or silty gravel with maximum thicknesses of approximately $15 \mathrm{~m}$. Bedrock lies at about $200 \mathrm{~m}$ depth. The landfill contains industrial and domestic waste dumped in several small gravel-pits between 1963 and 1973.

\section{DATA ACQUISITION AND ANALYSIS}

To determine the optimum time for data acquisition, background vibrational noise was continuously monitored on a 24-hr basis. The tests revealed that noise levels decreased significantly in the early evening and were sufficiently low after 20.00 . To further improve signal-to-noise ratios, different sources were tested. A dynamite charge of $100 \mathrm{~g}$ proved to be the best choice. Finally, an appropriate source-receiver geometry had to be determined. Based on the results of forward modeling through a series of "generic" waste disposal sites, receiver spacings of $2 \mathrm{~m}$ and source spacings of $8 \mathrm{~m}$ were chosen. Seismic data were then collected with a 24-bit Bison recording system employing up to 210 channels (see Table 1).

Data quality is generally very good, but the waveform characteristics of records recorded from shots located on and outside of the landfill differ markedly (Fig. 2). Signal-to-noise ratios are significantly lower for data generated and recorded on the landfill (Fig. 2a) than for those generated and recorded over undisturbed areas (Fig. 2b). Plots of reduced travel-time versus distance show similarly large differences. At distances greater than $-10 \mathrm{~m}$ the travel-time curves for data recorded inside and outside of the landfill start to diverge (Fig. 2c). The estimated surface velocity for both shots displayed in Figure 2 is $-500 \mathrm{~m} / \mathrm{s}$. Outside the landfill the velocities quickly increase to $>1000 \mathrm{~m} / \mathrm{s}$, whereas inside the velocities decrease to $<500 \mathrm{~m} / \mathrm{s}$. At distances $>20 \mathrm{~m}$ both travel-time curves indicate an average velocity of about $2000 \mathrm{~m} / \mathrm{s}$ (Fig. 2d). However, the curves for shots inside and outside the landfill are offset by 15 to $20 \mathrm{~ms}$, an effect that is clearly caused by the buried low velocity waste.

Consistent first arrival times are a critical requirement for reliable tomographic inversions. Initially, a semi-automatic picking scheme was used to determine estimates of $\sim 37,000$ onset times. Then we applied a cross-correlation algorithm to remove data errors and to refine onset times to better than $\sim 0.1 \mathrm{~ms}$. 
Portions of tomograms from lines 11 and q2 are shown in Figure 3. Since the lateral extent of the waste bodies are quite well known (Fig. 1), their identification on the tomograms should be relatively straightforward. We expect the landfill to be characterized by low velocities. On Figures $3 \mathrm{a}$ and $3 \mathrm{~b}$, we have highlighted the $1200 \mathrm{~m} / \mathrm{s}$ contour line, which approximately coincides with the base of both the low-velocity weathering layer and the landfill. Beneath line q2 (Fig. 3b), the landfill is delineated by a conspicuously thickened low-velocity zone between 0 and $120 \mathrm{~m}$. Likewise, it is visible on the 11 tomogram between 300 and $330 \mathrm{~m}$ (Fig. $3 a$ ). Where seen on the tomographic images (note, that very thin layers of waste beneath parts of line 11 cannot be discerned on the tomograms), the base of the landfill varies between 7 and $12 \mathrm{~m}$ depth relative to the surface. There is a good match of landfill depth estimates at the intersection of the two lines (marked with arrows in Figure 3). Along both lines, pronounced undulations of the landfill base reflect the irregular shape of the gravel pits before disposal of the waste. Due to the resolution limits of our travel-time data set, delineation of very shallow structures $(<5 \mathrm{~m})$ is not expected (i.e. in this depth range, the low-velocity weathering layer cannot be distinguished from the waste).

\section{CONCLUSIONS}

Results of our studies at Stetten have demonstrated the potential of refraction tomography for delineating relatively shallow (>5 m depth) velocity anomalies. An important pre-requisite for successful application of tomographic inversion techniques is a high-quality travel-time data set. Data quality can be optimized by taking advantage of noise and source tests, together with an appropriate first-break picking scheme. Determination of an optimum initial model is a critical element of the tomographic inversion process. The initial model is not only an important factor during the search in model space, but also defines the initial ray coverage and thus affects the resolution power.

\section{REFERENCES}

Kissling, E., Ellsworth, W.L., Eberhart-Phillips, D., Kradolfer, U., 1994: Initial reference models in local earthquake tomography, Journal of Geophysical Research, 99, 1963519646.

Lanz, E., Jemmi, L., Müller, R., Green, A., Pugin, A. and Huggenberger, P., 1994: Integrated studies of Swiss waster disposal sites: Results from georadar and other geophysical surveys, In Proceedings of the $5^{\text {th }}$ International Conference on Ground Penetrating Radar, Kitchener, Ontario, 3, 1261-1274.

Lanz, E., Pugin, A., Green, A., Horstmeyer, H., 1996: Results of 2- and 3-D high-resolution seismic reflection surveying of surficial sediments, Geophysical Research Letters, 23, 491-494.

Schneider, W.A. Jr., Ranzinger, K.A., Balch, A.H., Kruse, C., 1992: A dynamic programming approach to first arrival traveltime computation in media with arbitrarily distributed velocities, Geophysics, 57, 39-50.

\begin{tabular}{|l|l|}
\hline Source & $100 \mathrm{~g}$ dynamite \\
\hline Shot Spacing & $8 \mathrm{~m}$ \\
\hline Receiver Spacing & $2 \mathrm{~m}$ \\
\hline Sampling Interval & $0.25 \mathrm{~ms}$ \\
\hline Number of channels & 120 to 210 \\
\hline
\end{tabular}

Table 1: Recording Parameters 


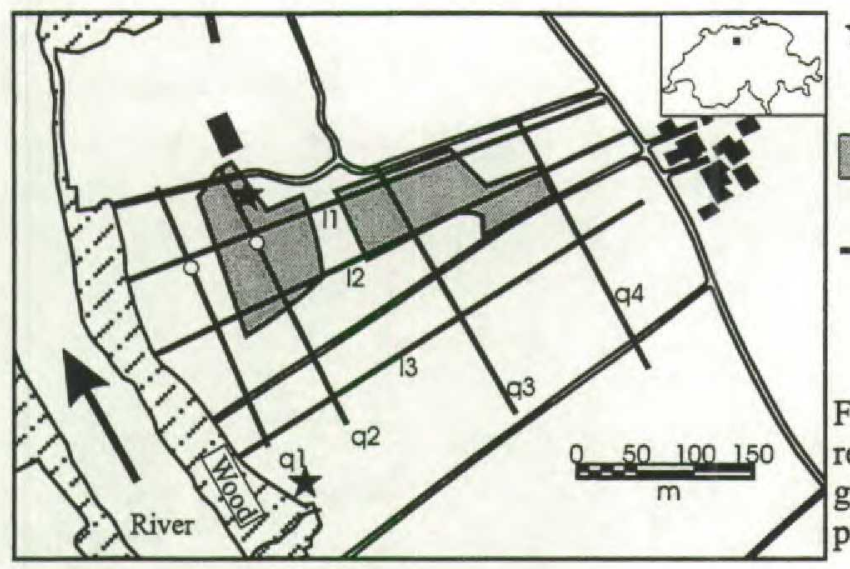

seismographs (noise tests)

location of shots of Fig. 2

waste disposal sites

(based on EM31 data)

refraction lines

Figure 1: Survey area showing the locations of the refraction lines as well as the shot points used to generate the sections in Figure 2. Tomograms for parts of lines 11 and $\mathrm{q} 2$ are shown in Figure 3.

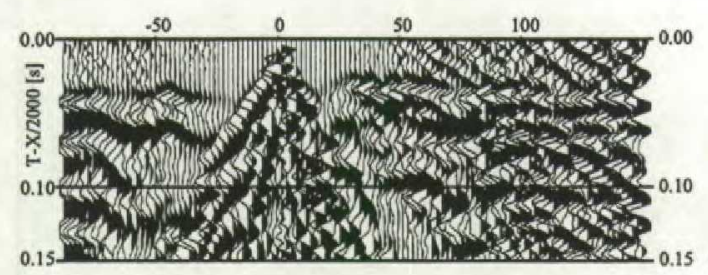

(a)
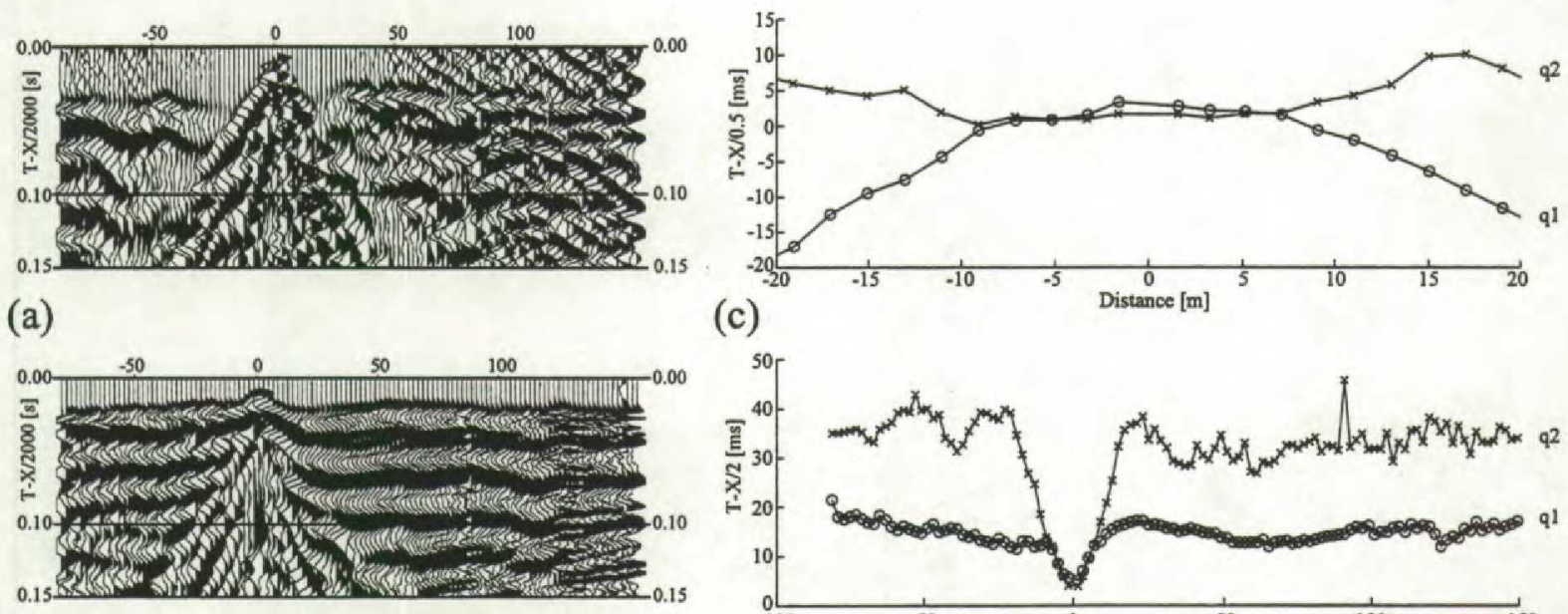

(c)

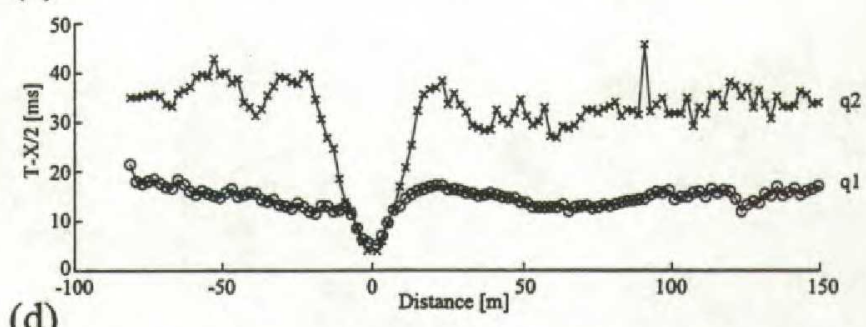

(b)

(d)

Figure 2: (a) Shot inside the landfill recorded along q2; (b) shot outside the landfill recorded along line q1; (c) comparison of travel times from the inside traces of Figures $2 \mathrm{a}$ and $2 \mathrm{~b}$; (d) comparsion of entire travel time data set in figures $2 \mathrm{a}$ and $2 \mathrm{~b}$. Data in (a), (b) and (d) are reduced with $2000 \mathrm{~m} / \mathrm{s}$, and in (c) with $500 \mathrm{~m} / \mathrm{s}$.

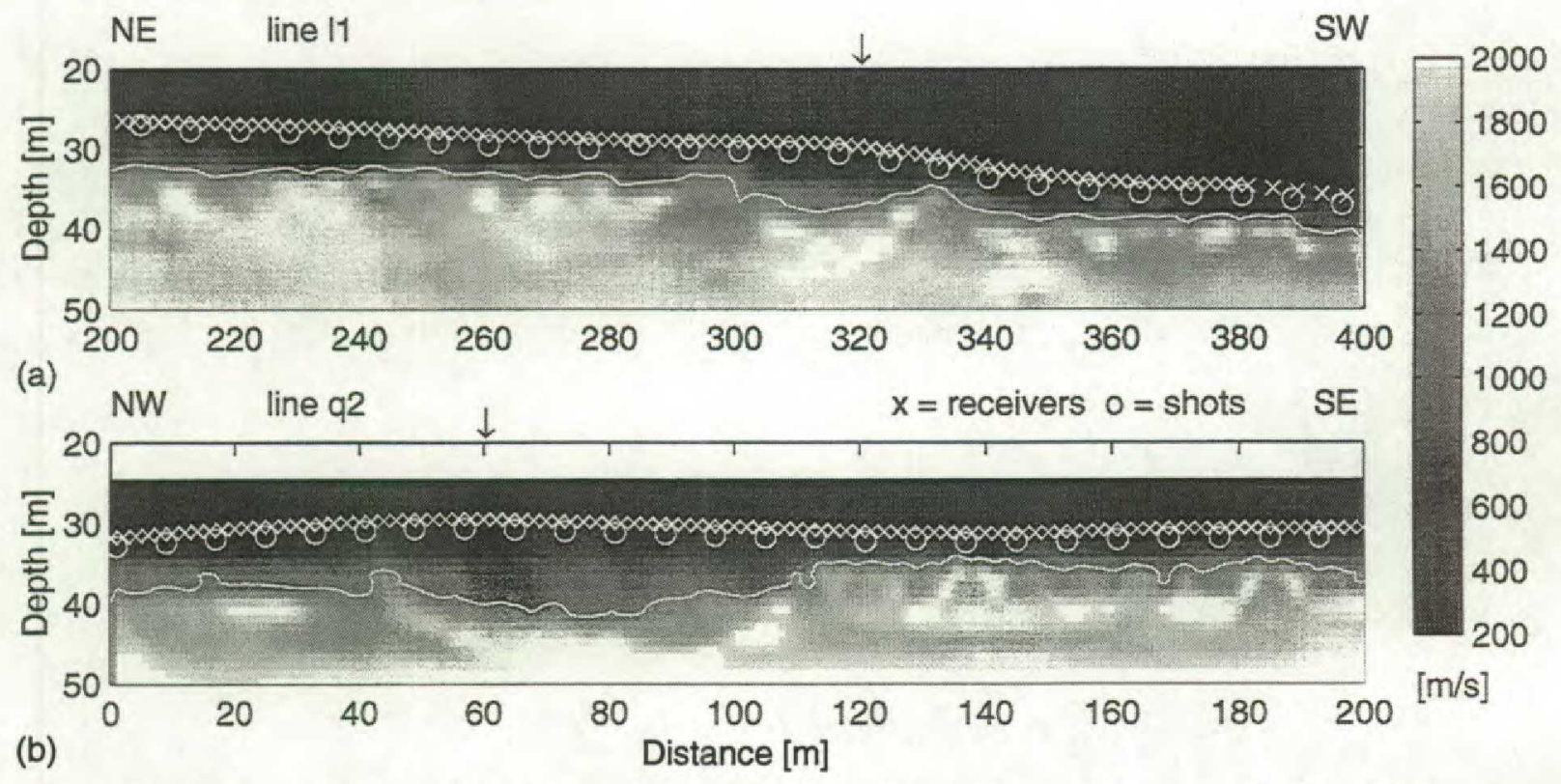

Figure 3: Tomograms for part of line 11 (section $200-400 \mathrm{~m}$ is shown of the $0-450 \mathrm{~m}$ long line) and q2 (section $0-200 \mathrm{~m}$ of the $0-240 \mathrm{~m}$ long line). The $1200 \mathrm{~m} / \mathrm{s}$ contour (fine white line) outlines approximate base of both the low velocity weathering layer and landfill. Vertical arrows show cross-over points of the two lines. Parts of the landfill are represented by low-velocity zones between 300 and $330 \mathrm{~m}$ beneath 11 and between 0 and $120 \mathrm{~m}$ beneath q2. 